\title{
INVESTIGATION OF EXPANSION CHARACTERISTICS OF CORONARY SLOT STENTS USING FINITE ELEMENT ANALYSIS
}

\author{
Xuanzhi Wang, Syed H. Masood \\ Industrial Research Institute Swinburne, Faculty of Engineering and Industrial Sciences, \\ Swinburne University of Technology, Hawthorn, Victoria, Australia 3122, \\ xuanzwang@yahoo.com.au
}

Abstract: Coronary stents are metallic tubes inserted in coronary arteries to treat cardiovascular diseases. The Palmaz-Schatz ${ }^{\mathbb{B}}$ Stent is the most representative member of the family of slot stents. In this paper, the impact of the geometry of the stent on its expansion behaviours was investigated using the ANSYS 9.0 finite element analysis (FEA) software. Several design cases, with the presence of a certain stenosed coronary artery, were selected for our research investigation. Results of the analysis, including expansion and radial displacement, radial recoil percentage, foreshortening percentage and von Mises stress distribution of various stents have been compared and discussed. This revealed significant potential relationships between the geometry of the stent and its expansion behaviours.

Key words: Angioplasty; Expansion characteristics; Finite Element Analysis; Simulation; Stent.

\section{INTRODUCTION}

Cardiovascular diseases constitute one of the major human health problems of modern times. Recently, the implantation of metallic coronary stents in the coronary artery has become an integral part of most interventional procedures for percutaneous revascularization'. The PalmazSchatz ${ }^{\circledR}$ stent (Johnson and Johnson Company, Warren, NJ, USA) is the most representative member of the family of slot stents. Much work ${ }^{2-5}$ has been done to investigate different expansion behaviours of stents with

Please use the following format when citing this chapter:

Wang, Xuanzhi, Masood, Syed, H., 2006, in International Federation for Information Processing (IFIP), Volume 207, Knowledge Enterprise: Intelligent Strategies In Product Design, Manufacturing, and Management, eds. K. Wang, Kovacs G., Wozny M., Fang M., (Boston: Springer), pp. 735-742. 
various geometries. To date, however, very little research work has investigated expansion characteristics of stents with various geometries with the presence of a stenosed artery. A methodology for studying expansion characteristics of stents with various geometries and the presence of a stenosed artery by the FEA method using ANSYS 9.0 will be presented in detail. Characteristics of stents with various geometries and the presence of a stenosed artery by the FEA method using ANSYS 9.0 will be presented in detail.

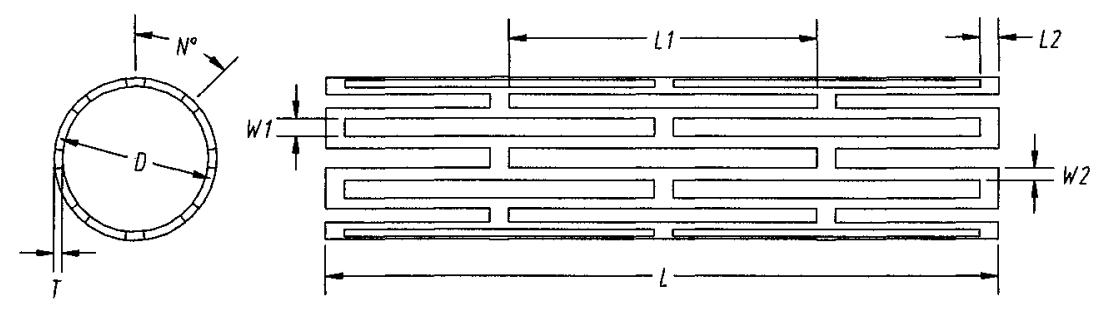

Figure 1. Geometric parameters of stent

\section{FINITE ELEMENT ANALYSIS OF STENTS}

In this investigation, seven varying designs of stent were modelled. It was assumed that all stents were equal in whole length $L$, thickness $T$ and mean diameter $D$. Figure 1 illustrates the geometric parameters of the stent: $L_{1}$ and $W_{1}$ are the slot length and slot width, $L_{2}$ and $W_{2}$ are the strut length and strut width, $D$ is stent thickness, $N$ is sector angle. Case 1 is the stent with standard geometry. Cases 2 and 3 are the stents with same stent width $W_{1}$ and strut width $W_{2}$ as Casel. However, Case 2 has shorter slots in which the slots were modelled to be $5 \%$ shorter than in Case 1 . Slots of Case 3, however, are 5\% longer than those of Case 1 . The slot length $L_{1}$ and strut length $L_{2}$ of Cases 4 and 5 are equal to those of Case 1. The slot width of Case 4, however, was decreased by $10 \%$, while that of Case 5 was increased by $10 \%$. The number of slots of Cases $1-5$ is 24 , while the number of slots of Cases 6 and 7 are 18 and 30, respectively, due to varying the sector angle $N$. Table 1 summarises the values of geometric parameters.

According to a typical environment and structure of a stenosed coronary artery $^{6}$, a three-dimensional model of a stent, a balloon, a fibrous cap, a lipid core and an arterial wall was created. To take advantage of these symmetric characteristics, a basic sector (see Figure 2) of it was used in the analysis using ANSYS 9.0 finite element analysis software. Thus, in the axial 
direction, a half sector of the model was selected, and in the circumferential direction, a sector of the model was selected.

Table I. Values of geometric parameters in seven cases

\begin{tabular}{llllllll}
\hline $\begin{array}{l}\text { Stent } \\
\text { design } \\
\text { case }\end{array}$ & $\begin{array}{l}\text { Slot } \\
\text { length } \\
\mathrm{L}_{1}(\mathrm{~mm})\end{array}$ & $\begin{array}{l}\text { Slot } \\
\text { width } \\
\mathrm{W}_{1}(\mathrm{~mm})\end{array}$ & $\begin{array}{l}\text { Strut } \\
\text { length } \\
\mathrm{L}_{2}(\mathrm{~mm})\end{array}$ & $\begin{array}{l}\text { Strut } \\
\text { width } \\
\mathrm{W}_{2}(\mathrm{~mm})\end{array}$ & $\begin{array}{l}\text { Stent } \\
\text { thickness } \\
\mathrm{D}(\mathrm{mm})\end{array}$ & $\begin{array}{l}\text { Sector } \\
\text { angle } \\
\mathrm{N}\left({ }^{\circ}\right)\end{array}$ & $\begin{array}{l}\text { Number } \\
\text { of slots }\end{array}$ \\
\hline 1 & 3.6200 & 0.2200 & 0.2200 & 0.1400 & 0.1000 & 45 & 24 \\
2 & 3.4390 & 0.2200 & 0.3407 & 0.1400 & 0.1000 & 45 & 24 \\
3 & 3.8010 & 0.2200 & 0.0993 & 0.1400 & 0.1000 & 45 & 24 \\
4 & 3.6200 & 0.1980 & 0.2200 & 0.1620 & 0.1000 & 45 & 24 \\
5 & 3.6200 & 0.2420 & 0.2200 & 0.1180 & 0.1000 & 45 & 24 \\
6 & 3.6200 & 0.2933 & 0.2200 & 0.1867 & 0.1000 & 60 & 24 \\
7 & 3.6200 & 0.1760 & 0.2200 & 0.1120 & 0.1000 & 36 & 24 \\
\hline
\end{tabular}

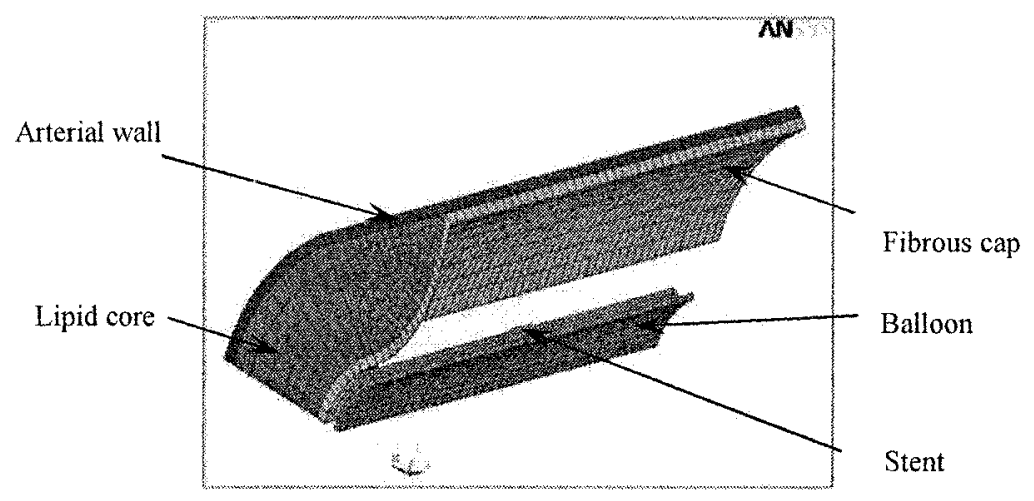

Figure 2. Finite Element Model

All five components were meshed using three dimensional 8-node solid brick elements. The material of the stent is stainless steel $316 \mathrm{~L}$. The material properties $^{7-11}$ of five components in the model are defined as Table 2.

Table 2. Material properties of components in model

\begin{tabular}{llllll}
\hline Component & Material model & $\begin{array}{l}\text { Young's } \\
\text { modulus } \\
(\mathrm{MPa})\end{array}$ & $\begin{array}{l}\text { Poisson's } \\
\text { ratio }\end{array}$ & $\begin{array}{l}\text { Yield } \\
\text { stress } \\
(\mathrm{MPa})\end{array}$ & $\begin{array}{l}\text { Tangent } \\
\text { modulus } \\
(\mathrm{MPa})\end{array}$ \\
\hline Balloon & Linear isotropic & $6.9 \times 10^{2}$ & 0.3 & - & - \\
Stent & Bilinear isotropic & $2.03 \times 10^{5}$ & 0.35 & $3.5 \times 10^{2}$ & $9.15 \times 10^{2}$ \\
Fibrous cap & Linear isotropic & 2.19 & 0.4999 & - & - \\
Lipid core & Linear isotropic & $1.74 \times 10^{-2}$ & 0.4999 & - & - \\
Arterial wall & Linear isotropic & 1.74 & 0.4999 & - & - \\
\hline
\end{tabular}


Three consecutive displacement ramped loads were applied in order on the inner surface of the balloon. From $0 \mathrm{~s}$ to $1.1 \mathrm{~s}$, a ramped radial displacement load was increased gradually from $0 \mathrm{~mm}$ to $1.1 \mathrm{~mm}$. From 1.1 $\mathrm{s}$ to $1.6 \mathrm{~s}$, a constant radial displacement load was maintained at $1.1 \mathrm{~mm}$. From $1.6 \mathrm{~s}$ to $2.7 \mathrm{~s}$, a ramped radial displacement load was decreased gradually from $1.1 \mathrm{~mm}$ to $0 \mathrm{~mm}$.

\section{RESULTS AND DISCUSSION}

\subsection{Radial displacement}

Figure 3 illustrates the radial displacement of various stents at the distal end at the corresponding simulation time obtained from the FEA. The radial displacement of the balloon is also shown as a reference.

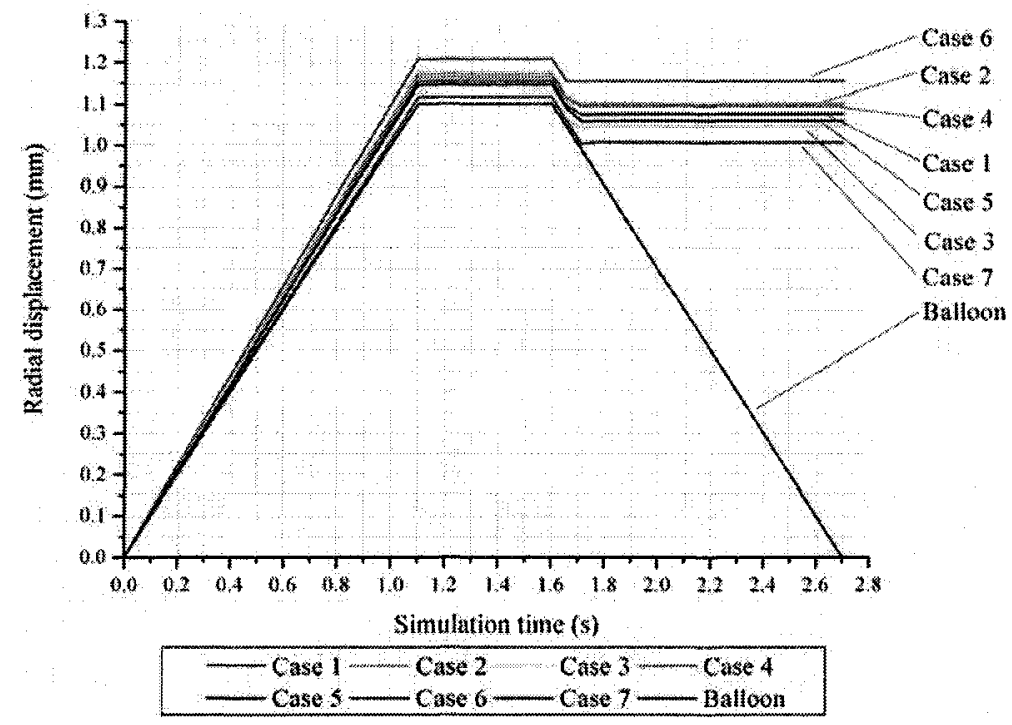

Figure 3. Radial displacement of various stents and balloon

In Case 1, opposite radial displacement characteristics were observed compared to Cases 2 and 3. The magnitude of the ultimate radial displacement of Case 2 was more than that of Case 1, while the magnitude of ultimate radial displacement of Case 3 was less than that of Case 1. It was revealed that decreasing the slot length enlarges the ultimate radial 
displacement, while increasing the slot length results in the reduction of the radial displacement.

Similar conclusions were observed in the impact of the changes of the slot width and slot length upon the radial displacement. It was shown that the change of the slot width has an opposite influence on the change of the ultimate radial displacement. The wider the slot was, the less the ultimate radial displacement.

Similar conclusions were also revealed in the influence of the number of slots on the radial displacement characteristic. The less the number of slots was, i.e. the larger the angle of the basic sector of the stent, the better radial displacement characteristic the stent had. The number of slots has a much more significant influence on radial displacement than other factors beyond the same displacement loading of the balloon.

\subsection{Radial recoil percentage}

By comparison of Cases 1,2 and 3, increasing or decreasing the slot length has the same impact trend on the magnitude of the recoil percentage, which resulted in reduction of the recoil. This revealed that the radial recoil percentage of Case 1 was near the extremum with the corresponding slot length. It was also concluded that the impact of the slot length on the recoil was less notable than other factors, because the slot length was the measurement along the axial direction, and the deformation and stress of the axial direction were far less than that of the radial direction.

From Cases 1, 4 and 5, it was seen that increase of the slot width enhances the recoil of the stent, while decrease of the slot has negative impact on the recoil. Because the slot width was a circumferential measurement, it played a more crucial role in the recoil characteristic than the slot length.

From Cases 1,6 and 7, it was observed that the number of slots was an important factor in the recoil characteristic of the stent. The recoil phenomenon in Case 7 was stronger than in Cases 1 and 6. More slots lead to small plastic deformation of the stent in a single slot under the same diameter of expansion, and as the major part of its deformation is elastic, so the stent was able to recover from the deformation easily.

\subsection{Foreshortening}

Figure 4 illustrates the radial displacement, i.e. foreshortening, of various stents at the distal end at the corresponding simulation time obtained from the FEA. The radial displacement of the balloon is also shown as a reference. 


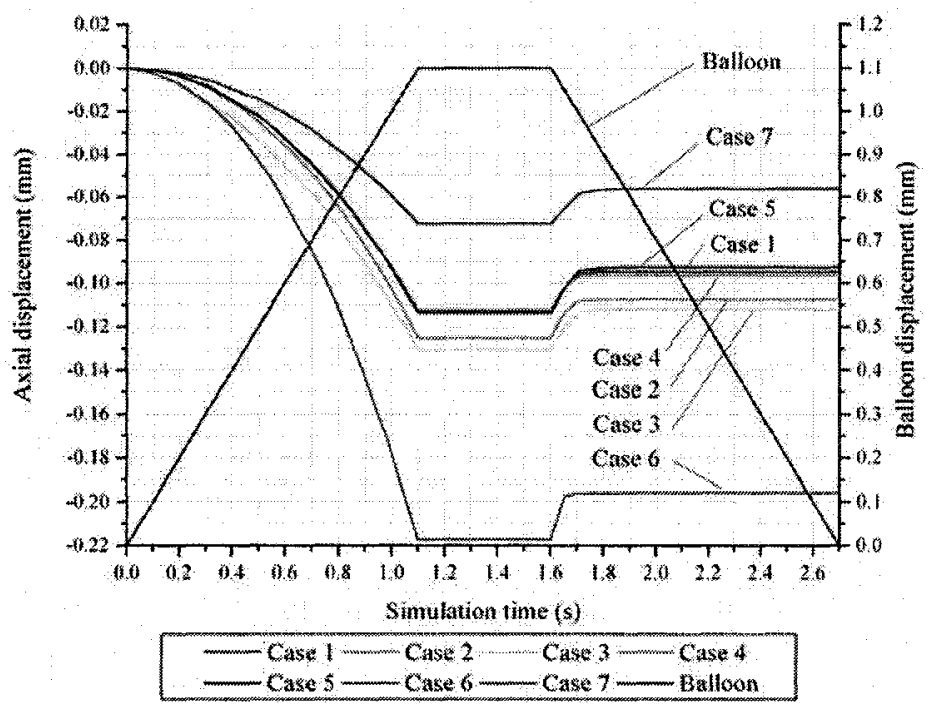

Figure 4. Axial displacement of various stents and balloon

By comparison of Cases 1, 2 and 3, both increasing and decreasing the slot length enhanced the foreshortening of the stent. This revealed that the value of the foreshortening of Case 1 was near the extremum with the corresponding slot length. Because the slot length was an axial measurement, it played a more crucial role in the recoil characteristic than the slot width.

From Cases 1, 4 and 5, it was seen that variety of the slot width has no significant impact on the foreshortening of the stent, because the slot width is the measurement along the conferential direction.

From Cases 1,6 and 7, it was observed that the number of slots was a crucial factor in the foreshortening of the stent. The foreshortening phenomenon of Case 6 was stronger than in Cases 1 and 7, because fewer slots resulted in more axial deformation of the stent in a single slot under the same diameter of expansion.

\section{4 von Mises stress distribution}

As shown in Figure 5 (a) (b) (c), from Cases 1, 2 and 3, it was revealed that there are more high stress areas in the stent with the longer slot. The low stress area in Case 2 was more than that of Case 1, especially at the end of the stent. The minimum stress of Case 2 was about half as much as that of Case 1. In Case 2, the slot was shorter and the strut was longer, which decreases the stress concentration and was propitious to decentralization of the stress. In Case 3, the high stress area occurs at the end of the stent as well. 
The minimum stress of Case 3 was in excess of twice of that of Case 1 . The longer slots and shorter strut meant that much stress was focused at the end and middle of the slots in Case 3. The results revealed that reducing the slot length, i.e. increasing the strut length, was able to significantly eliminate the concentration of stress and lessen its value.

As shown in Figure 5 (a) (d) (e), from Cases 1, 4 and 5, lower stress was found in the stent with a wider slot. In Case 4, with decreasing the slot width, the minimum value of stress was increasing notably. Narrower slots and a wider strut made the stent stiffer, which required more energy to deploy the stent. In Case 5 , by increasing the slot width, both minimum and maximum values of stress were reduced because of the improvement of flexibility of the stent. Even so the high stress area in the middle of the slots was enlarged to some extent. The results revealed that increasing the slot width was able to reduce the value of stress.

As shown in Figure 5 (a) (f) (g), from Cases 1, 6 and 7, the stress was dramatically decreased by adding the number of slots. In Case 6 , both the maximum and minimum values of stress were the largest in all cases, respectively. It required much more deformation for the stent with fewer slots, which resulted in the appearance of higher stress during the deformation. On the contrary, in Case 7, both the maximum and minimum values of stress were smallest in all cases, respectively. The results revealed that increasing the number of slots was able to reduce the value of stress.

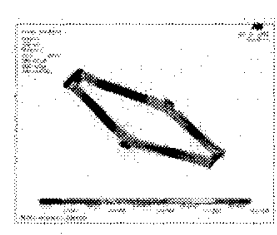

(a)

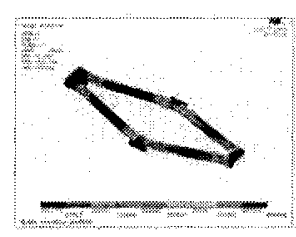

(b)



(c)

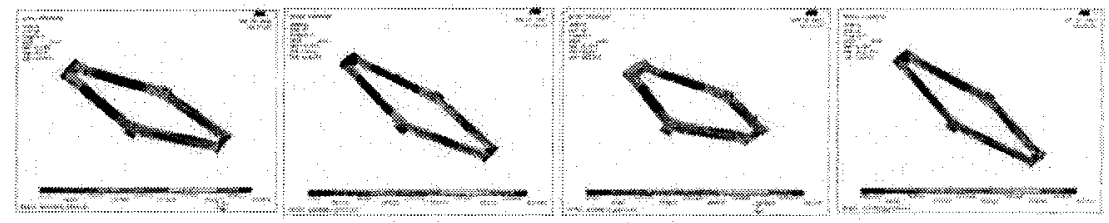

(d)

(e)

(f)

(g)

Figure 5. Distribution of von Mises stress of Stent 


\section{SUMMARY}

In this paper, a parametric model of a certain Palmaz-Schatz ${ }^{\circledR}$ stent has been developed by varying the slot length, slot width and number of slots. The expansion characteristics have been investigated by the FEA. Comparisons and discussions of these characteristics have revealed potential relationships between the geometry of the stent and its expansion characteristics. This study will provide better understanding of the structural characteristics of metallic stents from design and deployment points of view.

\section{REFERENCES}

1. A. Colombo, G. Stankovic and J. W. Moses, Selection of coronary stents, J. Am. Coll. Cardiol. 40(6), 1021-1033 (2002).

2. F. D. Whitcher, Simulation of in vivo loading conditions of nitinol vascular stent structures, Comp. \& Struct. 64(5), 1005-1011 (1997).

3. C. Dumoulin, and B. Cochelin, Mechanical behaviour modelling of balloon-expandable stents, J. Biomech. 33(11), 1461-1470 (2000).

4. S. N. D. Chua, B. J. MacDonald and M. S. J. Hashmi, Finite-element simulation of stent expansion, J. Mater. Process. Tech. 120(1), 335-340 (2002).

5. S. N. D. Chua, B. J. MacDonald and M. S. J. Hashmi, Finite element simulation of stent and balloon interaction, J. Mater. Process. Tech. 143-144, 591-597 (2003).

6. P. Libby, Atheroma: more than mush, Lancet. 348(Suppl. 1), s4-s7 (1996).

7. P. H. Grewe, K. M. Müler, T. Deneke, E. Harrer, A. Germing, A. Müge, and B. Lemke, Stents: material, surface texture and design, in theory and practice, Minim. Invasive. Ther. Allied. Technol. 11(4), 157-163 (2002).

8. K. Mori and T. Saito, Effects of stent structure on stent flexibility measurements, Annals. Biomed. Eng. 33(6), 733-742 (2005).

9. C. Rogers, D. Y. Tseng, J. C. Squire and E. R. Edelman, Balloon-artery interactions during stent placement: a finite element analysis approach to pressure, compliance, and stent design as contributors to vascular injury, Circ. Res. 84(4), 378-383 (1999).

10. A. I. Veress, D. G. Vince, P. M. Anderson, J. F. Cornhill, E. E. Herderick, J. D. Klingensmith, B. D. Kuban, N. L. Greenberg and J. D. Thomas, Vascular mechanics of the coronary artery, Z. Kardiol. 89(Suppl. 2), 92-100 (2000).

11. R. A. Baldewsing, C. L. de Korte, J. A. Schaar, F. Mastik and A. F. van der Steen, Finite element modeling and intravascular ultrasound elastography of vulnerable plaques: parameter variation, Ultrasonics. 42(1-9), 723-729 (2004) 